\title{
Effect of thermal degradation on rheological properties of polymeric materials
}

\author{
Jozef Dobránsky ${ }^{1, *}$, Zigmund Doboš ${ }^{1}$ \\ ${ }^{1}$ Technical University of Košice, Faculty of Manufacturing Technologies with a seat in Prešov, \\ Department of Automotive and Manufacturing Technologies, Štúrova 31, 08001 Prešov, Slovak \\ Republic
}

\begin{abstract}
The aim of this paper is to monitor the melt volume index of thermoplastic materials and other rheological properties such as shear rate and viscosity. The aim is to compare and assess whether several times ground and subsequently re-melted samples of pure polymer granulate will have the same or similar rheology properties and whether adjustment of the injection molding machine will be required or will need to reduce or increase production times. Thermo Scientific with HAAKE Meltflow MT software was used to determine the melt flow rate index (MVR) of thermoplastic materials. Based on the melt flow rate (MVR), shear rate and viscosity evaluation, it has been found that, although the selected materials have undergone multiple changes in the rheology of the polymeric materials, there is no problem in the molding process, and MVR does not change significantly. In this case, no changes in the settings of the injection molding machines and reduction or increase in production times will be necessary. When re-melting the granulate samples, no excess waste was generated, which would then need to be disposed of and the samples could be re-used for further measurement after grinding.
\end{abstract}

\section{Introduction}

Rheology deals with the flow and deformation of materials under the influence of force. The flow properties of materials are measured using a rheometer [1]. Rheological properties are determined for all types of materials. This includes liquid substances, semi-solids and solids. It is especially used for measuring flow properties of polymers. The most commonly used rheological method for determining the flow properties of polymeric materials is a measurement of the deformation of a bulk sample using a mechanical rheometer.

Viscosity and viscoelasticity are among the basic rheological properties of commonly used materials. They vary depending on external conditions. These outdoor conditions include stress, tension, time course, and temperature. The rheological properties affect all phases of use of individual materials. These phases include the preparation of materials, their processing and subsequent performance. The choice of rheometer is very important. It depends on rheological properties such as shear rate, shear stress, viscosity and sample size. The timing of measurement also plays a role [2].

\footnotetext{
*Corresponding author: jozef.dobransky@tuke.sk
} 
It is important to know that changing the batch material significantly affects its rheological properties. This also affects its processing. Even the small variability of the material significantly affects the processing process. Small changes in the polymer structure significantly affect the polymer melt rheology. Therefore, rheology is one of the most suitable methods for characterizing polymers. A small change the molecular weight of the polymer can dramatically alter the polymer's processing behaviour $[3,4]$.

\section{Experimental equipment, procedure and material}

This chapter deals with the description of tested materials, equipment a methods used in experiment.

\subsection{Tested materials}

Five different thermoplastic materials were used to assess the effect of thermal degradation on rheological properties. All of these materials are used in the automotive industry to produce automotive applications by injection molding technology.

\section{HOSTACOM M2 N01}

Hostacom M2 N01 is a 20\% talc filled polypropylene (PP) homopolymer, with low melt flow rate and good stiffness. This grade is delivered in natural color version. Material Melt Mass-Volume Rate $\left(230^{\circ} \mathrm{C} / 5.0 \mathrm{~kg}\right)$ is $10.0 \mathrm{~cm}^{3} / 10 \mathrm{~min}$ [5].

\section{MAKROLON® 2805}

Polycarbonate (PC) thermoplastic material; easy release, variety purpose; medium viscosity; injection molding; colours: transparent, translucent and opaque. Material Melt Mass-Volume Rate $\left(300{ }^{\circ} \mathrm{C} / 1.2 \mathrm{~kg}\right)$ is $9.0 \mathrm{~cm}^{3} / 10 \mathrm{~min}$. Drying conditions: $\left(120^{\circ} \mathrm{C} / 2-3 \mathrm{~h}\right)[5]$.

\section{DURETHAN ${ }^{\circledR}$ BKV30H2.0}

Polyamide 6 (PA6) filled with $30 \%$ glass fibers, injection molding, heat-aging stabilized. Material Melt Mass-Volume Rate $\left(260{ }^{\circ} \mathrm{C} / 5.0 \mathrm{~kg}\right)$ is $16.0 \mathrm{~cm}^{3} / 10 \mathrm{~min}$. Drying conditions: $\left(80^{\circ} \mathrm{C} / 2-6 \mathrm{~h}\right)[5]$.

\section{NOVODUR® $\mathrm{H802}$}

Novodur ${ }^{\circledR}$ H802 is a high heat injection molding grade Acrylonitrile Butadiene Styrene with high stiffness, especially suitable for being painted. Novodur is used for automotive rear lamp housings and automotive decorations. Material Melt Mass-Volume Rate $\left(220^{\circ} \mathrm{C}\right.$ $/ 10.0 \mathrm{~kg}$ ) is $8.0 \mathrm{~cm}^{3} / 10 \mathrm{~min}$. Drying conditions: $(80 \% 2-4 \mathrm{~h})$ [5].

\section{G-BLEND 85 PC/ABS}

Non-reinforced, amorphous thermoplastic polymer blend. Blend based on Polycarbonate (PC) and Acrylonitrile butadiene styrene (ABS). Excellent properties: toughness, rigidity and ability to flow and mould easily. Material Melt Mass-Volume Rate $\left(260{ }^{\circ} \mathrm{C} / 5.0 \mathrm{~kg}\right)$ is $19.0 \mathrm{~cm}^{3} / 10 \mathrm{~min}$. Drying conditions: $\left(90-100{ }^{\circ} \mathrm{C} / 2-4 \mathrm{~h}\right)$ [5]. 
Table 1 shows the MVR values for the individual materials and test conditions.

Table 1. Marking of the batch of test materials.

\begin{tabular}{|c|c|}
\hline Marking of batch & Batch \\
\hline 0 & virgin material (without thermal degradation) \\
\hline 1 & material after the first thermal degradation \\
\hline 2 & material after the second thermal degradation \\
\hline 3 & material after the third thermal degradation \\
\hline 4 & material after the fourth thermal degradation \\
\hline 5 & material after the fifth thermal degradation \\
\hline 6 & material after the sixth thermal degradation \\
\hline
\end{tabular}

\subsection{Measurement of melt volume-flow rate of thermoplastics (MVR)}

The melt volume flow rate (MVR) can be defined as the melt extrusion rate through a capillary tube of defined length and diameter under specified conditions. These conditions include: temperature, load and position of the piston in the rheometer cylinder. The rate is calculated as the volume of the substance pushed out at a particular time. The MVR unit is $\mathrm{cm}^{3} / 10 \min [6]$.

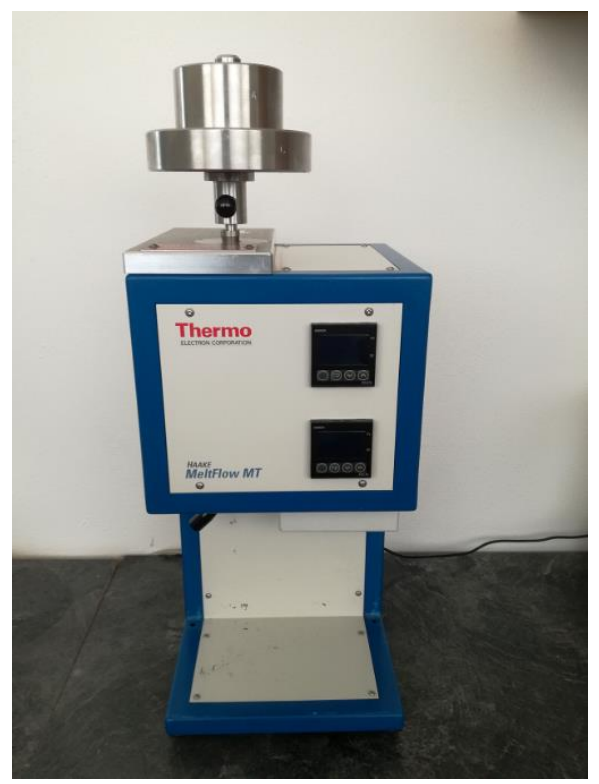

Fig. 1. Termo Haake Meltflow MT melt indexer.

The EN ISO 1133 standard deals with the determination of the melt volume flow rate of thermoplastics. The standard specifies specific procedures. The weight or volume of the extruded thermoplastic sample can be determined. The method of bulk melt flow rate is used to compare materials with different filler contents and to compare filled and unfilled thermoplastics [7].

These methods are used for thermoplastics with special rheological behaviour. They are used if rheological behaviour during measurement is influenced by various phenomena. These phenomena include: hydrolysis, condensation or crosslinking. They can only be used to a limited extent. Assuming that the repeatability and reproducibility of the results is to an 
acceptable extent. The melt volume flow rate was determined by a Termo Haake Meltflow MT rheometer (Fig. 1) [8,9].

\section{Results and discussion}

\section{HOSTACOM M2 N01}

Figure 2 shows the dependence of MVR on thermal degradation of the material with the trade name Hostacom M2 N01. The material did not need to be dried before testing as the material is not hygroscopic.

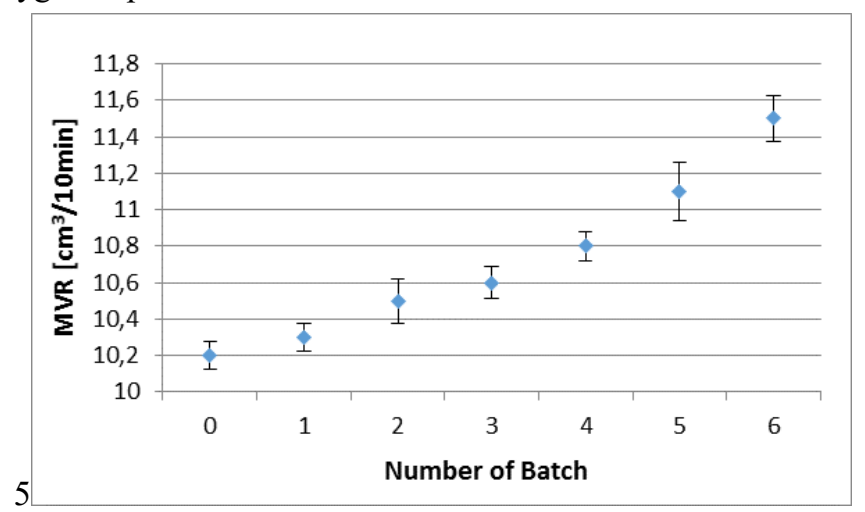

Fig. 2. Dependence of MVR on thermal degradation for material Hostacom.

As can be seen in Figure 2, multiple re-melting of the material at least affects the MVR value. The MVR value represents 10.2 for virgin material. During thermal degradation, the MVR value gradually increased to 11.5 for batch 6 . This represents an increase of $12.7 \%$.

\section{MAKROLON® 2805}

Figure 3 shows the dependence of MVR on thermal degradation of the material with the trade name Makrolon 2805. The material was dried in the oven before testing under the conditions mentioned above in the description of the material.

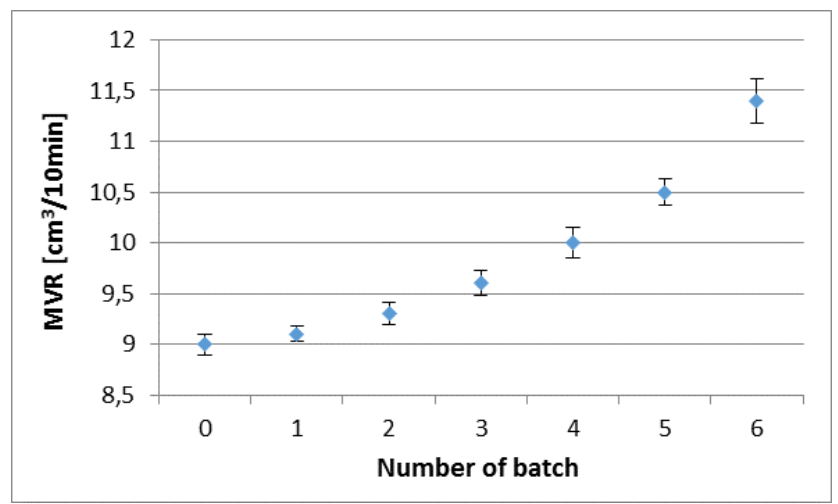

Fig. 3. Dependence of MVR on thermal degradation for material Makrolon.

In Figure 3 we can see a similar trend as in the previous material. MVR value gradually increased from 9.0 to 11.4 . This represent an increase of $26.7 \%$ what is still in the norm. 


\section{DURETHAN ${ }^{\circledR}$ BKV30H2.0}

Figure 4 shows the dependence of MVR on thermal degradation of the material with the trade name Durethan ${ }^{\circledR}$ BKV30H2.0. The material was dried in the oven before testing under the conditions mentioned above in the description of the material.

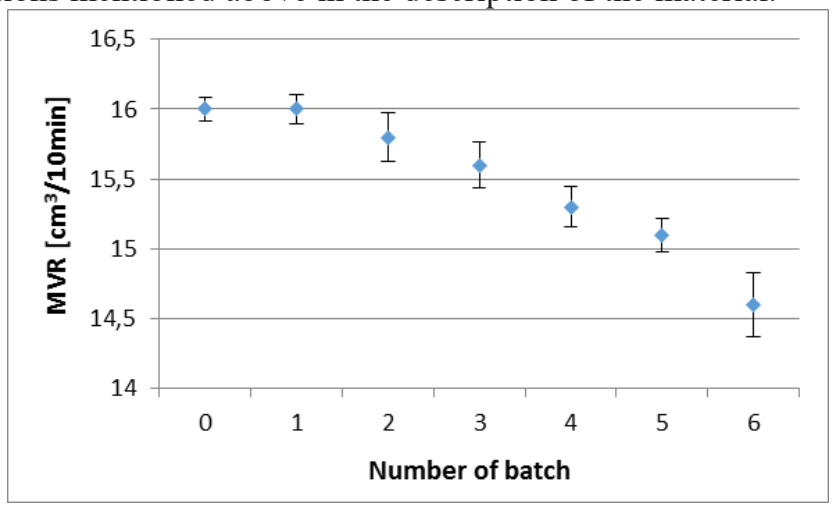

Fig. 4. Dependence of MVR on thermal degradation for material Durethan.

Figure 4 shows a downward trend. MVR gradually decreased from 16 for virgin material to 14.6 for batch 6 . It represents a minimum decrease of $8.8 \%$.

\section{NOVODUR® $\mathrm{H802}$}

Figure 5 shows the dependence of MVR on thermal degradation of the material with the trade name Novodur ${ }^{\circledR}$ H802. The material was dried in the oven before testing.

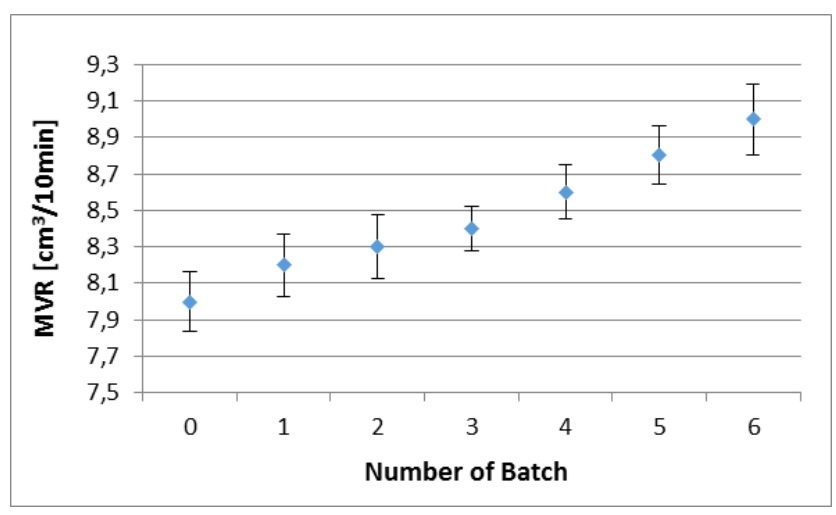

Fig. 5. Dependence of MVR on thermal degradation for material Novodur.

We can see the minimal increase in MVR in Figure 5. MVR gradually increased from 8 for virgin material to 9 for batch 6 . It represents a minimum decrease of $12.5 \%$.

\section{G-BLEND 85 PC/ABS}

Figure 6 shows the dependence of MVR on thermal degradation of the material with the trade name G-Blend $85 \mathrm{PC} / \mathrm{ABS}$. The material was dried in the oven before their testing. MVR gradually decreased from 19 to 18,3 that represents 3,7 \%. 


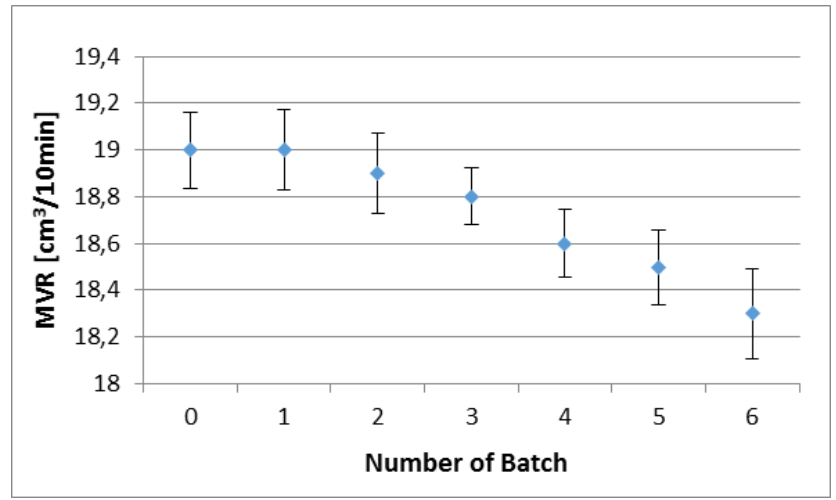

Fig. 6. Dependence of MVR on thermal degradation for material G-Blend.

\section{Summary}

Overall, multiple thermal degradation does not significantly affect the rheological properties of the materials studied. In this case, no changes in the settings of the injection molding machines and reduction or increase in production times will be necessary.

This work was supported by the project with No. 004TUKE-4/2017 Implementation of research from mathematical modelling of microgeometry surface relation on consequential qualitatively parameters part produced with cutting machining into subjects of new study programme Technology of automotive production.

\section{References}

1. A. Panda, J. Duplák, J. Jurko, Analytical expression of T-v(c) dependence in standard ISO 3685 for cutting ceramic, Key Engineering Materials 480-481, 317-322 (2011)

2. Z. Murcinkova, P. Baron, L, Tino, M. Pollak, J. Murcinko, Research and analysis of stress distribution in multilayers of coated tools, International Journal of Materials Research 108, 495-506 (2017)

3. J. Macala, I. Pandová, A. Panda, Zeolite as a prospective material for the purification of automobile exhaust gases, Mineral Resources Management 33, 125-137 (2017)

4. E.A. Maksimov, R. Krehel', M. Pollak, Prospective systems and technologies for the treatment of wastewater containing oil substances, Clean Technologies and Environmental Policy 18, 161-170 (2016)

5. https://plastics.ulprospector.com/

6. M. Ovsik, A. Mizera, M. Manas, L. Hylova, M. Bednarik, M. Stanek, The Effect of Irradiation on Mechanical and Thermal Properties of Selected Types of Polymers, Polymers 10, 1-22 (2018)

7. STN EN ISO 1133 - Plastics. Determination of the melt mass-flow rate (MFR) and melt volume-flow rate (MVR) of thermoplastics. Part 1: Standard method

8. M. Ovsik, D. Manas, M. Manas, M. Stanek, M. Hribova, K. Kocman, D. Samek, M. Manas, Irradiated Polypropylene Studied by Microhardness and Waxs, Chemicke listy 106, S507-S510 (2012)

9. M. Boruvka, L. Behalek, P. Lenfeld, C. Ngaowthong, M. Pechociakova, Structurerelated properties of bionanocomposites based on poly(lactic acid), cellulose nanocrystals and organic impact modifier, Materials Technology 34, 143-156 (2019) 